Published in final edited form as:

Ann Epidemiol. 2013 August ; 23(8): . doi:10.1016/j.annepidem.2013.05.014.

\title{
Time away from work predicts later cognitive function: Differences by activity during leave
}

\author{
Anja K. Leist, $\mathrm{PhD}^{1,2}$, M Maria Glymour, ScD ${ }^{3}$, Johan P Mackenbach, MD, PhD ${ }^{2}$, Frank J \\ van Lenthe, $\mathrm{PhD}^{2}$, and Mauricio Avendano, $\mathbf{P h D}^{2,3,4}$
}

${ }^{1}$ University of Luxembourg, Faculty of Language and Literature, Humanities, Arts and Education, Walferdange, Luxembourg ${ }^{2}$ Erasmus Medical Center, Department of Public Health, Rotterdam, Netherlands ${ }^{3}$ Harvard School of Public Health, Department of Social and Behavioral Sciences, Boston, USA ${ }^{4}$ London School of Economics and Political Science, Department of Social Policy, LSE Health and Social Care, London, United Kingdom

\begin{abstract}
Purpose-To examine how different activities performed during employment gaps are associated with later cognitive function and change.

Method-Five cognitive measures were used to indicate cognitive impairment of 18,259 respondents to the Survey of Health, Ageing, and Retirement in Europe (age 50-73) in 2004/5 or 2006/7. Using complete employment histories, employment gaps of six months or more between ages 25 and 65 were identified.
\end{abstract}

Results-Controlling for early-life socioeconomic status, school performance, and education, higher risk of cognitive impairment was associated with employment gaps described as unemployment (Odds Ratio [OR] $=1.18,95 \%$ Confidence Interval [CI] 1.04, 1.35) and sickness $(\mathrm{OR}=1.78,95 \% \mathrm{CI} 1.52,2.09)$. In contrast, lower risk of cognitive impairment was associated with employment gaps described as training $(\mathrm{OR}=0.73,95 \%$ CI $0.52,1.01)$ or maternity $(\mathrm{OR}=$ $0.65,95 \%$ CI $0.57,0.79)$. In longitudinal mixed effects models, training and maternity spells were associated with lower two-year aging-related cognitive decline.

Discussion-Periods away from work described as unemployment or sickness are associated with lower cognitive function, whereas maternity and training spells are associated with better late-life cognitive function. Both causation and selection mechanisms may explain these findings.

\section{Keywords}

cognition; cognitive reserve; employment status

\footnotetext{
(C) 2013 Elsevier Inc.

Corresponding Author: Anja K. Leist, PhD, University of Luxembourg, Faculty of Language and Literature, Humanities, Arts and Education, Route de Diekirch, L-7220 Walferdange, Luxembourg., Phone: +352-46 664495 81, Mobile: +49-163 7354734, anja.leist@uni.lu.

Publisher's Disclaimer: This is a PDF file of an unedited manuscript that has been accepted for publication. As a service to our customers we are providing this early version of the manuscript. The manuscript will undergo copyediting, typesetting, and review of the resulting proof before it is published in its final citable form. Please note that during the production process errors may be discovered which could affect the content, and all legal disclaimers that apply to the journal pertain.

Author Contributions:

All authors were involved in design and conceptualization of the study. Anja Leist is principal investigator, she analyzed and interpreted data and wrote the draft of the paper. M. Maria Glymour, Johan Mackenbach, Frank van Lenthe, and Mauricio Avendano revised the draft. All authors were involved in data interpretation. All authors approved of this version of the paper.
} 


\section{INTRODUCTION}

Education and working-life occupational complexity are associated with cognitive function in older age [1-5]. Cognitive reserve is the result of accumulated experiences throughout the lifecourse [6-9] and could be influenced by prolonged periods of cognitively stimulating activities either in or out of the workplace. Predominant activities performed during employment gaps may thus predict cognitive function at older age. Periods out of work for training may promote cognitive reserve directly or indirectly by providing opportunities for career advancement and higher socioeconomic status (SES). Similarly, maternity spells may provide opportunities for long-term engagement in social relationships and reduce workfamily strain, which in the long run may promote cognitive reserve. In contrast, gaps without clearly defined or purposeful activities, such as unemployment or sickness may reduce cognitive reserve directly by limiting opportunities for cognitively demanding activities, or indirectly via less social participation or lower SES. Predictions of how homemaking could influence cognitive function are less straightforward. To our knowledge, the long-term impact of labor market involvement on later cognitive function and change has not been fully explored yet. Differentiating activities during leave may help to disentangle the mechanisms linking labor market inactivity to cognitive function in later life.

Based on complete work histories and extensive cognitive assessments among respondents to the Survey of Health, Ageing and Retirement in Europe (SHARE) in 13 countries, we examined how employment gaps associated with unemployment, sickness, homemaking, training, and maternity spells relate to cognitive function and aging-related cognitive decline at older age.

\section{METHODS}

\section{Survey of Health, Ageing, and Retirement in Europe (SHARE)}

Data came from the longitudinal population representative SHARE survey, which provides comparable information on health, employment, and social conditions of Europeans aged 50 and older. The survey has been described in detail elsewhere [10]. A German internal review board (IRB) has approved of ethical standards, study design and data collection [11]. Analyses have been conducted with 18,418 respondents of age 50 or older at time of the first interview from 13 countries (Austria, Germany, Sweden, Netherlands, Spain, Italy, France, Denmark, Greece, Switzerland, Belgium, Czech Republic, and Poland) who had completed the life-history assessment SHARELIFE in 2008/9. Sample numbers per country ranged from $n=539(2.9 \%)$ for Austria to $n=2,016(10.9 \%)$ for Greece. Only respondents younger than 75 years at the time of SHARELIFE were selected, entering the survey in 2004 (wave $1 ; n=11,465$ ) or 2006/2007 (wave $2 ; n=6,989$ ). Older participants were excluded to prevent possible selective attrition and risk of recall biases at older ages. A total of 18,259 respondents had three or more non-missing values on the five cognitive tests and were included in the cross-sectional analyses. Cognitive test scores of 9,880 respondents were available from both waves (see Table 1).

\section{Working-life economic inactivity periods}

Data on work histories came from SHARELIFE, which collected detailed retrospective lifehistories expanding through early childhood until last interview. Employment histories were assessed using the lifegrid method [12] to identify employment gaps from age 15 through last interview with a life history calendar. Economic inactivity was defined as period out of the labor market lasting six months or longer since leaving education or since age 15; respondents were asked to report the activity that best described their situation during the gap. We included spells in-between jobs and spells after the last job that occurred between 
ages 25 to 65 . We identified having had at least one spell of unemployment, sickness or disability, homemaking, training or further fulltime education, and maternity spells of women lasting six months or longer as forms of economic inactivity.

\section{Cognitive function}

Cognitive function was assessed by five measures $[13,14]$ at SHARE entry in 2004 or 2006/7: Verbal fluency was assessed by naming as many animals as possible in one minute [5]. Immediate recall was assessed by asking respondents to recall as many words as possible from a ten-word list that had been read out loud once by the interviewer immediately before, delayed recall was assessed by asking the same list after a standardized interval. Orientation was assessed by asking respondents the correct day of month, day of the week, month, and year. Numeracy was assessed by five arithmetical calculation tasks. A summary cognitive function score of averaged $\mathrm{z}$-scores of the five tests was built for individuals who had valid values for at least three of the tests. For longitudinal analyses, the summary score was built using wave 1 mean and standard deviation. In cross-sectional analyses, respondents were classified as being cognitively impaired if their score was in the lowest decile of the summary indicator.

\section{Early and late life factors}

We controlled for early life factors that could operate as confounders, assessed in 2008/9 [5]. Childhood SES was operationalized by the reported number of books in the household at age 10 in quintiles, a dichotomized deprivation score indicating availability of less than two items of household equipment at age 10 (fixed bath, cold running water supply, hot running water supply, inside toilet, central heating), and main breadwinner's occupation at age 10. The International Standard Classification of Occupation information (ISCO major groups) of main breadwinner's occupation was summarized as categorical variable with professional and managers, intermediate or lower supervisors, clerks, lower sales and services, lower technical and routine workers, and missing information [15]. Retrospective reports of school performance were operationalized as self-rated mathematical skills and language skills at age 10 relative to others. Educational attainment was measured based on national educational classifications and subsequently standardized using the International Standard Classification of Education (ISCED) [16]. ISCED information of respondents assessed at SHARE entry was regrouped as categorical variable with up to lower secondary education $(n=7,791)$, upper secondary $(n=5,798)$, tertiary $(n=4,475)$, and a separate category of those with missing information $(n=195)$.

Later-life SES and health were considered as late life confounders with potentially mediating role [17], addressing our research question with a highly conservative approach. SES was assessed by income, wealth, and occupation of last job. Wealth was operationalized as household total net worth, defined as sum of financial and housing wealth minus liabilities; household income included income from all household members. Missing items for income and wealth were imputed [10]. To account for number of household members, values were divided by the square root of household members. Non-Euro values were converted and adjusted for purchasing power parity in the interview year. Income and wealth were categorized into country-specific quintiles. ISCO information of last job was assessed in 2008/9 and regrouped into same categories as for breadwinner's occupation.

Adult health was measured based on three complementary baseline assessments. Participants were asked to rate their health according to the ordinal categories 'excellent', 'very good', 'good', 'fair', and 'poor'. We measured disability as one or more limitation on any of Instrumental Activities of Daily Living (IADL). Using mobility indices or Activities of Daily Living produced comparable results. Individuals were asked whether they had been 
diagnosed with heart attack, high blood pressure or hypertension, high blood cholesterol, stroke, and diabetes or high blood sugar.

\section{Statistical analysis}

Analyses used pooled data for all countries as country-specific sub-samples were too small; all models were instead adjusted for country indicator variables. The analysis was carried out in two steps. First, cross-sectional models were conducted modeling cognitive impairment assessed at SHARE entry as a function of reports of economic inactivity spells using logistic regressions. All models included types of economic inactivity, country indicators, age and gender as covariates (model 1), additionally including early life factors (model 2), and baseline health and socioeconomic status measures (model 3).

To help address the possibility that patterns in the cross-sectional analyses reflected reverse influences of prior cognitive function on inactivity spells, we implemented longitudinal models as supplementary analyses. These patterns should be interpreted cautiously because of short follow-up period and limited statistical power. We used mixed (random-effects) models to assess age-related cognitive decline based on two successive assessments across a two-year period. To maximize statistical power, we used age at assessment as time scale for these models (exploiting within and between individual variations). The model was specified with individual-level random intercepts and fixed effects for country, gender, age (centered), occurrence of economic inactivity, an interaction term of age and the economic inactivity variable (model 1), plus early life factors (model 2), and late life factors (model 3). The coefficient of the age-inactivity interaction term indicates the association of economic inactivity with aging-related cognitive decline, the parameter of interest in these models. Results for men and women were similar and therefore only pooled results are reported. In analyses involving maternity spells, only women ever having had children were included to compare mothers with and without prolonged maternity spell.

All analyses were conducted using weights accounting for the complex sampling design and controlling for the inverse probability of being included in wave 1 or 2 and surviving until the SHARELIFE interview in 2008/9. Analyses were carried out using SPSS version 19.

\section{RESULTS}

\section{Descriptive results}

Table 1 shows sample characteristics for the entire sample ( $\mathrm{n}=9,900$ female, $54.2 \%)$. Mean age was 59 years, and $78 \%$ reported to be married. Over $90 \%$ of the sample had had at least one employment spell, and $32 \%$ of respondents reported that they were still working in 2008/2009. Overall, $58.7 \%$ of respondents experienced at least one spell of economic inactivity at ages 25 to 65 . Frequencies of reported economic inactivity periods ranged from $7 \%$ for training to $19 \%$ for maternity spells of women lasting six months or more.

Prevalence of cognitive impairment varied according to the history of economic inactivity spells (Table 2).

\section{Cross-sectional analyses with cognitive impairment as outcome}

In model 1, with covariates country, age, and gender, occurrence of unemployment, sickness, and homemaker spells were associated with increased risk of cognitive impairment $\left(\mathrm{OR}_{\text {unemployment }} 1.17,95 \%\right.$ CI 1.04, 1.33; OR $_{\text {sickness }} 2.32,95 \%$ CI 2.00, 2.70; $\mathrm{OR}_{\text {homemaker }}$ $1.60,95 \% \mathrm{CI} 1.41,1.82)$. Training and maternity spells were associated with lower risk of cognitive impairment $\left(\mathrm{OR}_{\text {training }} 0.46,95 \%\right.$ CI $0.33,0.62$; $\mathrm{OR}_{\text {maternity }} 0.60,95 \%$ CI 0.50 , 0.72). After including early life factors (model 2), associations of unemployment, sickness, homemaker, and maternity spells with risk of cognitive impairment were attenuated and CIs 
were wider, but patterns remained quite similar. Additionally adjusting for adult socioeconomic, health measures, and risk factors known to cause cognitive impairment (model 3), attenuated associations of sickness, homemaker, and training spells with cognitive impairment included the null. However, occurrence of unemployment was associated with higher risk of cognitive impairment (OR1.19, $95 \%$ CI 1.04, 1.36), whereas maternity spells were associated with lower risk of cognitive impairment (OR0.70, 95 \% CI $0.57,0.85$ ). We conducted supplementary analyses stratifying by occupational class, as effects might differ for workers with different skill levels. A separate set of analyses testing the interaction of employment gaps and occupational title revealed significant interactions for unemployment and sickness spells. Further analyses stratified by occupational category showed that unemployment and sickness spells were associated with higher odds of cognitive impairment for respondents in higher occupations (Appendix table 1).

\section{Mixed effects models with cognitive function as outcome}

Separate mixed models were used to examine the association between each type of economic inactivity and two-year change in the summary measure of cognitive function (averaged z-scores of five cognitive tests), controlling for country, age, gender (Table 4), plus early life confounders (model 2), and late life factors (model 3; Table 5). Estimates for age correspond to a ten-year difference. Older age was associated with worse cognitive function in all models (in the model for unemployment, $\beta_{\text {age per decade }}=-0.157, \mathrm{p}<0.001$ ). Adjusted for early life factors, unemployment and sickness spells were associated with lower cognitive function, but unexpectedly with slower aging-related decline $\left(\beta_{\text {age }} \times\right.$ unemployment $=0.038, p<0.05 ; \beta_{\text {age }} \times$ sickness $\left.=0.070, p<0.01\right)$. Training and maternity spells also predicted slower aging-related cognitive decline $\left(\beta_{\text {age }} \times\right.$ training $=0.068$, $p<0.01, \beta_{\text {age }} \times$ maternity $=0.034, p<0.05$ ). Adjusted for late-life factors (model 3), only the association of training with slower aging-related cognitive decline was statistically significant $(\beta=0.075, p<0.05)$.

\section{Sensitivity analyses}

A potential concern in the analysis is selective non-response due to severe cognitive impairment and recall bias at older age. As cognitive impairment is relatively rare before age 70 , we first tested the robustness of results by running the analyses for respondents aged 5070 only. Results were also unchanged after excluding respondents in the lowest decile of cognitive function. Patterns were similar if respondents reporting never having been in paid employment were excluded, if we controlled for first occupation as marker for cognitive reserve during early adulthood, or if all types of economic inactivity were analyzed in a single model. Analyses stratified by European region (Western, South, Northern, Eastern Europe) yielded qualitatively comparable results with imprecise CIs. Finally, physical inactivity and depression may be associated with both work inactivity and cognitive function and thus act as potential confounder. Incorporating physical inactivity (never moderate or vigorous activity) and depression (EURO D-caseness [18]) in Model 3, results were essentially unchanged in both cross-sectional and longitudinal models (results available upon request).

\section{DISCUSSION}

Our findings suggest that spells of work inactivity in adult life are associated with cognitive function at older age, but the direction of this association depends on the activity performed during the employment gap. Unemployment or sickness spells were associated with higher risk of cognitive impairment and lower cognitive function. In contrast, training and maternity spells were associated with both lower risk of cognitive impairment and lower aging-related decline. These associations held for maternity spells after adjusting for 
baseline socioeconomic status, health, and risk factors known to cause cognitive impairment. Overall, results suggest potential for midlife cognitive activities to influence cognitive function at older age. However, we cannot rule out the possibility that unobserved early or midlife risk factors for later cognitive decline also affect employment histories.

\section{Explanation of results}

Causation mechanisms may partly contribute to our findings. After adjusting for attrition, sampling design, and early life conditions, employment gaps described as unemployment spells were associated with higher risk of cognitive impairment at older age. Earlier research has shown that job loss is associated with ill health [19-22], less favorable career pathways, and long-term declines in annual earnings [23]. A period of unemployment may limit opportunities for intellectual activity via cognitively demanding tasks [3]. In cross-sectional analyses, adult health and socioeconomic factors attenuated, but did not substantially reduce the association of unemployment and health, suggesting that unemployment spells, for which individuals do not report purposeful activities such as training or child raising may partly contribute to lower cognitive function in later life. This should be interpreted cautiously because we found no evidence that unemployment spells were associated with faster age-related decline.

Employment gaps described as sickness or homemaking were associated with higher risk of cognitive impairment, but these associations were largely explained by adult health and socioeconomic conditions, suggesting that any effects of inactivity periods due to sickness are partly attributable to health conditions such as stroke, which directly compromises cognitive function [24]. Individuals with temporary economic inactivity reported as sickness or homemaking may not achieve the SES of individuals with stable work trajectories [25], which in turn may influence later-life cognitive function. Longitudinal models did not support direct effects of these inactivity spells on cognitive function.

Inactivity spells for maternity leave were associated with lower risk of cognitive impairment and slower aging-related decline. In contrast to homemaker spells, maternity spells reflected temporary economic inactivity suggesting potentially greater diversity of life-course tasks across periods of childraising and employment. In addition, prolonged maternity leave during the potentially stressful period raising an infant may have protected women from the stress of multiple marital, parental, and work roles [26], leading to better mental health [27, 28]. Our results suggest that maternity spells may additionally be promoting cognitive reserve up to older age.

Employment gaps due to training may ultimately lead to higher SES. A training spell could also promote cognitive function directly by allowing individuals to engage in cognitively stimulating activities, whose benefits may remain beyond working ages. Concordance of cross-sectional and longitudinal findings suggests that benefits of training on cognitive function are not only beneficial through higher SES, but that training is promoting cognitive reserve in later life directly as well.

Selection mechanisms may contribute to some of our findings. Individuals with lower early life cognitive function and lower education may more often be laid off involuntarily [29], may have a lower occupation [30] and a less stable and thus unfavorable employment trajectory compared to individuals with higher cognitive function [31, 32]. Employment characteristics such as supervisory experience may influence cognitive function [33, 34]. Long-term selection by early cognitive function cannot totally be ruled out. However, including a set indicators of cognitive reserve and childhood SES [35] in longitudinal models showed that selection into inactivity due to these factors may partly but not fully 
explain our findings, especially considering that associations of inactivity due to training and maternity with cognitive decline held up in longitudinal analyses.

Poor working-life health may also increase chances of economic inactivity, although for women, health selection effects of homemaker spells have not been found [36]. Other unmeasured contextual factors may select into voluntary inactivity, such as spousal earnings, maternity benefits, or labor market situation $[37,38]$. There is ample evidence that unemployment leads to psychological problems and distress [39], which in turn can lead to cognitive impairment. Evidence from human and animal studies suggests chronic stress is associated with neurotoxicity and adverse brain changes [40, 41]. Further, links of depression and cognitive impairment have been shown [42]. Though we could not control for depression during working ages, results did not change after including baseline depression, with the association of inactivity due to training with lower cognitive decline holding up in longitudinal analyses.

\section{Methodological considerations}

Strength of our study was the use of complete histories of employment and multiple cognitive assessments. However, several limitations should be considered. Our measure of cognitive impairment during relatively early old age is likely to reflect the lower range of statistically 'normal' cognitive function, not necessarily clinically diagnosable disorders. Results might differ for measures of mild and severe cognitive impairment in the oldest old. The main activity performed during each employment gap was based on self-reports and differs from the reason triggering the employment gap. Some activities such as training can be considered more specific or purposeful than employment gaps reported as unemployment or sickness. However, considering our interest in how employment gaps differ in their potential to increase cognitive reserve, being able to exploit information on the activities performed during employment gaps was very useful. Lack of specific or purposeful activities of unemployment or sickness spells may even be one of the reasons for the associations of these spells with cognitive impairment. Future studies should investigate pathways from single employment gaps to cognitive impairment in more detail and ideally consider reason for leave, more detailed descriptions of performed activities during the spell, and personal evaluations of activities during the spell such as their purposefulness.

In analyses stratified by occupational class, we found that unemployment and sickness spells had stronger negative effects on cognitive function for higher-skilled workers. A possible explanation is that higher-skilled workers experience a larger loss of cognitive stimulation at work when leaving the labor market, compared to lower-skilled workers in less cognitively stimulating occupations. Future studies measuring occupational complexity should assess whether this might explain differences by occupational class.

Longitudinal models confirmed the association of maternity and training spells with better cognitive function. In contrast, unemployment and sickness spells were associated with slower aging-related cognitive decline, suggesting selection mechanisms may account for associations observed in the cross-sectional analyses.

\section{CONCLUSIONS}

Employment gaps may promote but also reduce cognitive function in older age. In particular, leaves reported as unemployment and sickness are associated with higher risk of cognitive impairment indicating potential deteriorative associations of these types of economic inactivity. In contrast, training and maternity spells are associated with lower risk of cognitive impairment and slower cognitive decline. Further research based on prospective 
longitudinal data is needed to isolate selection and causation mechanisms in the association between economic inactivity and cognitive function.

\section{Acknowledgments}

Dr. Anja K. Leist is supported by the Fonds National de la Recherche, Luxembourg (grant INTER/FLARE2/10/01). Dr. M. Maria Glymour currently receives funding from the National Institutes of Health (grant AG040248-01, PI: Lisa Berkman), the American Heart Association, the Telemedicine Advanced Technology Research Center, the Robert Wood Johnson Foundation Health and Society Scholars program, and the Harvard University Program on the Global Demography of Aging. Dr. Mauricio Avendano is supported by a Starting Researcher grant from the European Research Council (ERC) (grant No 263684), with additional support from the National Institute on Aging (grants R01AG037398 and R01AG040248), the McArthur Foundation Research Network on Ageing and a Eurfellowship from the Erasmus University. Dr. Johan P. Mackenbach and Dr. Frank J. van Lenthe report no disclosures.

This paper uses data from SHARELIFE release 1, as of November 24th 2010 or SHARE release 2.5.0, as of May 24th 2011. The SHARE data collection has been primarily funded by the European Commission through the 5th framework programme (project QLK6-CT-2001- 00360 in the thematic programme Quality of Life), through the 6th framework programme (projects SHARE-I3, RII-CT- 2006-062193, COMPARE, CIT5-CT-2005-028857, and SHARELIFE, CIT4-CT-2006-028812) and through the 7th framework programme (SHARE-PREP, 211909 and SHARE-LEAP, 227822). Additional funding from the U.S. National Institute on Aging (U01 AG09740-13S2, P01 AG005842, P01 AG08291, P30 AG12815, Y1-AG-4553-01 and OGHA 04-064, IAG BSR06-11, R21 AG025169) as well as from various national sources is gratefully acknowledged (see http://www.share-project.org for a full list of funding institutions).

\section{List of Abbreviations}

$\begin{array}{ll}\text { SES } & \text { socioeconomic status } \\ \text { SHARE } & \text { Survey of Health, Ageing, and Retirement in Europe } \\ \text { ISCO } & \text { International Standard Classification of Occupation } \\ \text { ISCED } & \text { International Standard Classification of Education } \\ \text { IADL } & \text { Instrumental Activities of Daily Living } \\ \text { OR } & \text { odds ratio } \\ \text { CI } & \text { confidence interval }\end{array}$

\section{REFERENCES}

1. Andel R, Vigen C, Mack WJ, Clark LJ, Gatz M. The effect of education and occupational complexity on rate of cognitive decline in Alzheimer's patients. J Int Neuropsychol Soc. 2006; 12:147-152. [PubMed: 16433954]

2. Bickel H, Kurz A. Education, occupation, and dementia: The Bavarian School Sisters Study. Dement Geriatr Cogn Disord. 2009; 27:548-556. [PubMed: 19590201]

3. Finkel D, Andel R, Gatz M, Pedersen NL. The role of occupational complexity in trajectories of cognitive aging before and after retirement. Psychol Aging. 2009; 24:563-573. [PubMed: 19739912]

4. Kröger E, Andel R, Lindsay J, Benounissa Z, Verreault R, Laurin D. Is complexity of work associated with risk of dementia? Am J Epidemiol. 2008; 167:820-830. [PubMed: 18263600]

5. Lee S, Kawachi I, Berkman LF, Grodstein F. Education, other socioeconomic indicators, and cognitive function. Am J Epidemiol. 2003; 157:712-720. [PubMed: 12697575]

6. Salthouse, TA. Theoretical perspectives on cognitive aging. Hillsdale, NJ, England: Lawrence Erlbaum Associates, Inc; 1991.

7. Hultsch DF, Hertzog C, Small BJ, Dixon RA. Use it or lose it: Engaged lifestyle as a buffer of cognitive decline in aging? Psychol Aging. 1999; 14:245-263. [PubMed: 10403712] 
8. Stern Y. What is cognitive reserve? Theory and research application of the reserve concept. J Int Neuropsychol Soc. 2002; 8:448-460. [PubMed: 11939702]

9. Scarmeas N, Stern Y. Cognitive reserve and lifestyle. J Clin Exp Neuropsychol. 2003; 25:625-633. [PubMed: 12815500]

10. Börsch-Supan, A.; Brugiavini, A.; Jürges, H., et al. Health, ageing and retirement in Europe. Mannheim: Mannheim Research Institute for the Economics of Aging (MEA); 2005.

11. Börsch-Supan, A.; Jürges, H. The Survey of Health, Aging, and Retirement in Europe Methodology. Mannheim: Mannheim Research Institute for the Economics of Aging (MEA); 2005.

12. Berney LR, Blane DB. Collecting retrospective data: Accuracy of recall after 50 years judged against historical records. Soc Sci Med. 1997; 45:1519-1525. [PubMed: 9351141]

13. Dewey, ME.; Prince, MJ. Cognitive function. In: Börsch-Supan, A., et al., editors. Health, Ageing and Retirement in Europe - First Results from the Survey of Health, Ageing and Retirement in Europe. Mannheim: MEA; 2005. p. 108-117.

14. Ofstedal, MB.; Fisher, GG.; Herzog, RA. Documentation of Cognitive Functioning Measures in the Health and Retirement Study. HRS Documentation Report DR-006 [online]. Available. Accessed July 4th, 2012 from http://hrsonline.isr.umich.edu/sitedocs/userg/dr-006.pdf

15. ISCO International Standard Classification of Occupation. Major, minor and unit groups. [online]. Available. Accessed June 28, 2012, from http://www.ilo.org/public/english/bureau/stat/isco/ isco58/major.htm

16. ISCED International Classification of Education. Available. Accessed June 28, 2012, from http:// www.uis.unesco.org/Education/Pages/international-standard-classification-of-education.aspx

17. Ferrie JE, Kivimäki M, Westerlund H, et al. Differences in the association between sickness absence and long-term sub-optimal health by occupational position: a 14-year follow-up in the GAZEL cohort. Occup Environ Med. 2011; 68:729-733. [PubMed: 21242277]

18. Prince MJ, Reischies F, Beekman AT, et al. Development of the EURO-D scale--a European Union initiative to compare symptoms of depression in 14 European centres. The Brit J Psychiat. 1999; 174:330-338.

19. Gallo WT, Teng HM, Falba TA, Kasl SV, Krumholz HM, Bradley EH. The impact of late career job loss on myocardial infarction and stroke: a 10 year follow up using the health and retirement survey. Occup Environ Med. 2006; 63:683-687. [PubMed: 16798871]

20. Gallo WT, Bradley EH, Falba TA, et al. Involuntary job loss as a risk factor for subsequent myocardial infarction and stroke: Findings from The Health and Retirement Survey. Am J Ind Med. 2004; 45:408-416. [PubMed: 15095423]

21. Gallo WT, Brand JE, Teng H-M, Leo-Summers L, Byers AL. Differential impact of involuntary job loss on physical disability among older workers. Res Aging. 2009; 31:345-360. [PubMed: 19924265]

22. Gallo WT, Bradley EH, Siegel M, Kasl SV. Health effects of involuntary job loss among older workers. J Gerontol B Psychol Sci Soc Sci. 2000; 55:S131-S140. [PubMed: 11833981]

23. Sullivan D, von Wachter T. Job displacement and mortality: An analysis using administrative data. Q J Econ. 2009; 124:1265-1306.

24. Rasquin S, Lodder J, Ponds R, Winkens I, Jolles J, Verhey FRJ. Cognitive functioning after stroke: A one-year follow-up study. Dement Geriatr Cogn Disord. 2004; 18:138-144. [PubMed: 15211068]

25. Smith JP. The impact of socioeconomic status on health over the life-course. Hum Resour. 2007; XLII:739-764.

26. Martikainen P. Women's employment, marriage, motherhood and mortality: A test of the multiple role and role accumulation hypotheses. Soc Sci Med. 1995; 40:199-212. [PubMed: 7899932]

27. Chatterji P, Markowitz S. Does the length of maternity leave affect maternal health? South Econ J. 2005; 72:16-41.

28. Staehelin K, Bertea P, Stutz E. Length of maternity leave and health of mother and child - a review. Int J Public Health. 2007; 52:202-209. [PubMed: 18030952]

29. Kokko K, Pulkkinen L, Puustinen M. Selection into long-term unemployment and its psychological consequences. Int J Behav Dev. 2000; 24:310-320. 
30. Schmidt FL, Hunter J. General mental ability in the world of work: Occupational attainment and job performance. J Pers Soc Psychol. 2004; 86:162-173. [PubMed: 14717634]

31. Virtanen M, Kivimäki M, Joensuu M, Virtanen P, Elovainio M, Vahtera J. Temporary employment and health: a review. Int J Epidemiol. 2005; 34:610-622. [PubMed: 15737968]

32. Virtanen P, Vahtera J, Broms U, Sillanmäki L, Kivimäki M, Koskenvuo M. Employment trajectory as determinant of change in health-related lifestyle: the prospective HeSSup study. Eur J Public Health. 2008; 18:504-508. [PubMed: 18515862]

33. Virtanen M, Singh-Manoux A, Ferrie JE, et al. Long working hours and cognitive function. Am J Epidemiol. 2009; 169:596-605. [PubMed: 19126590]

34. Schmand B, Smit JH, Geerlings MI, Lindeboom J. The effects of intelligence, education on the development of dementia. A test of the brain reserve hypothesis. Psychol Med. 1997; 27:13371344. [PubMed: 9403905]

35. Glymour MM, Avendaño M, Haas S, Berkman LF. Lifecourse social conditions and racial disparities in incidence of first stroke. Ann Epidemiol. 2008; 18:904-912. [PubMed: 19041589]

36. Ross CE, Mirowsky J. Does employment affect health? J Health Soc Behav. 1995; 36:230-243. [PubMed: 7594356]

37. Genda Y, Kondo A, Ohta S. Long-term effects of a recession at labor market entry in Japan and the United States. J Hum Resour. 2010; 45:157-196.

38. Henriksson KM, Lindblad U, Ågren B, Nilsson-Ehle P, Råstam L. Associations between unemployment and cardiovascular risk factors varies with the unemployment rate: The Cardiovascular Risk Factor Study in Southern Sweden (CRISS). Scand J Public Health. 2003; 31:305-311. [PubMed: 15099037]

39. Paul KI, Moser K. Unemployment impairs mental health: Meta-analyses. J Vocat Behav. 2009; 74:264-282.

40. Lupien SJ, McEwen BS, Gunnar MR, Heim C. Effects of stress throughout the lifespan on the brain, behaviour and cognition. Nat Rev Neurosci. 2009; 10:434-445. [PubMed: 19401723]

41. Gianaros PJ, Jennings JR, Sheu LK, Greer PJ, Kuller LH, Matthews KA. Prospective reports of chronic life stress predict decreased grey matter volume in the hippocampus. NeuroImage. 20007; 35:795-803. [PubMed: 17275340]

42. Airaksinen E, Larsson M, Lundberg I, Forsell Y. Cognitive functions in depressive disorders: evidence from a population-based study. Psychol Med. 2004; 34:83-91. [PubMed: 14971629] 


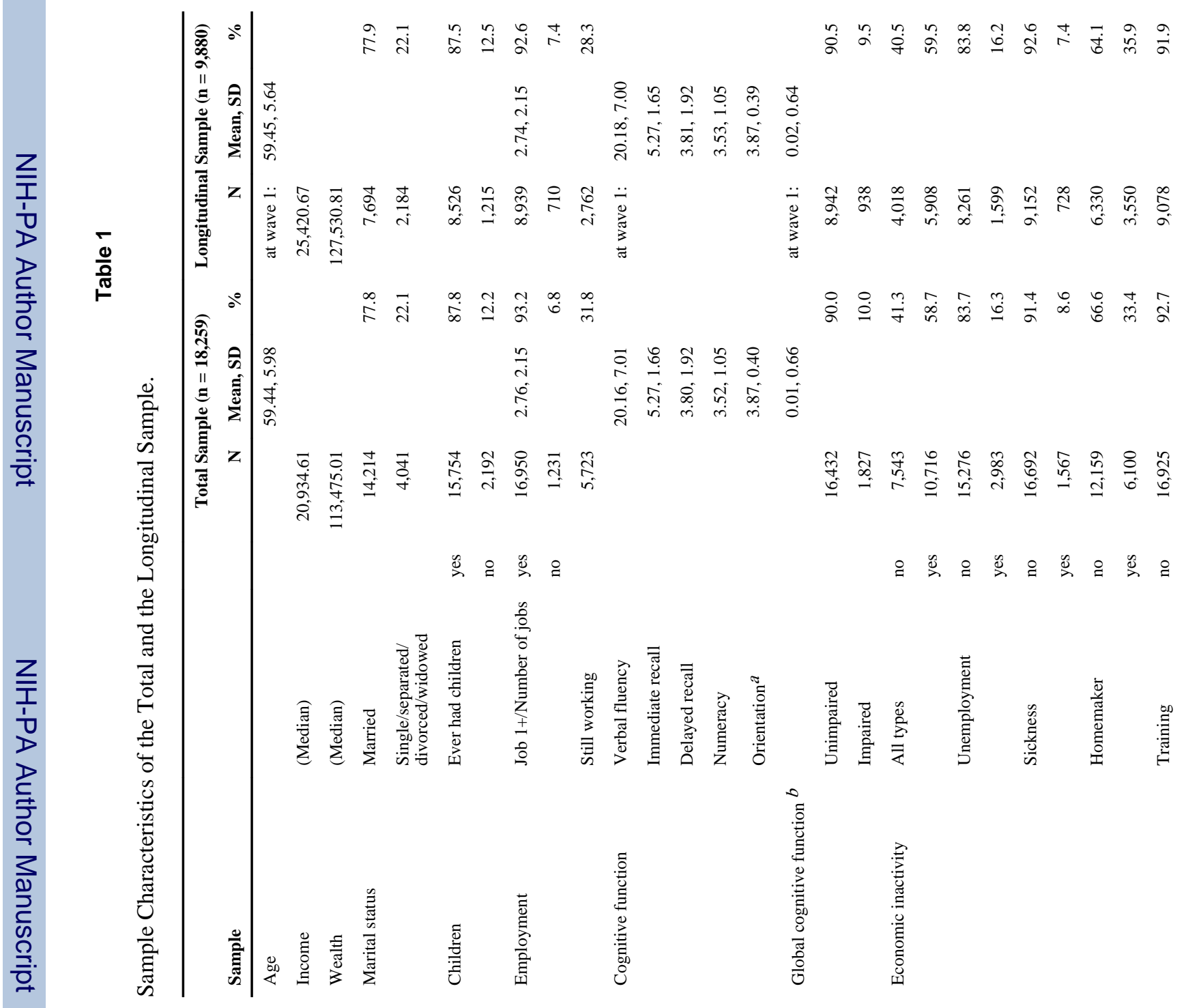
Ann Epidemiol. Author manuscript; available in PMC 2014 August 01. 


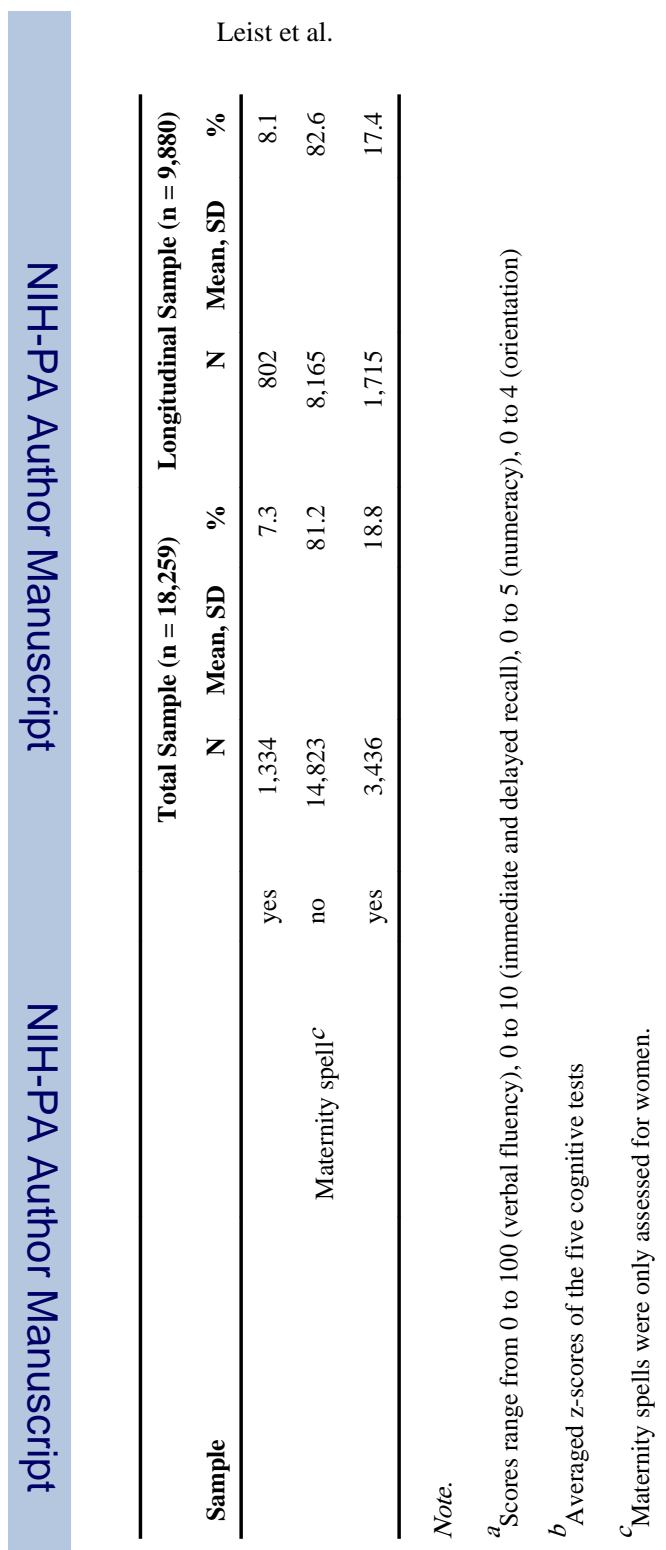

Page 12

Ann Epidemiol. Author manuscript; available in PMC 2014 August 01. 


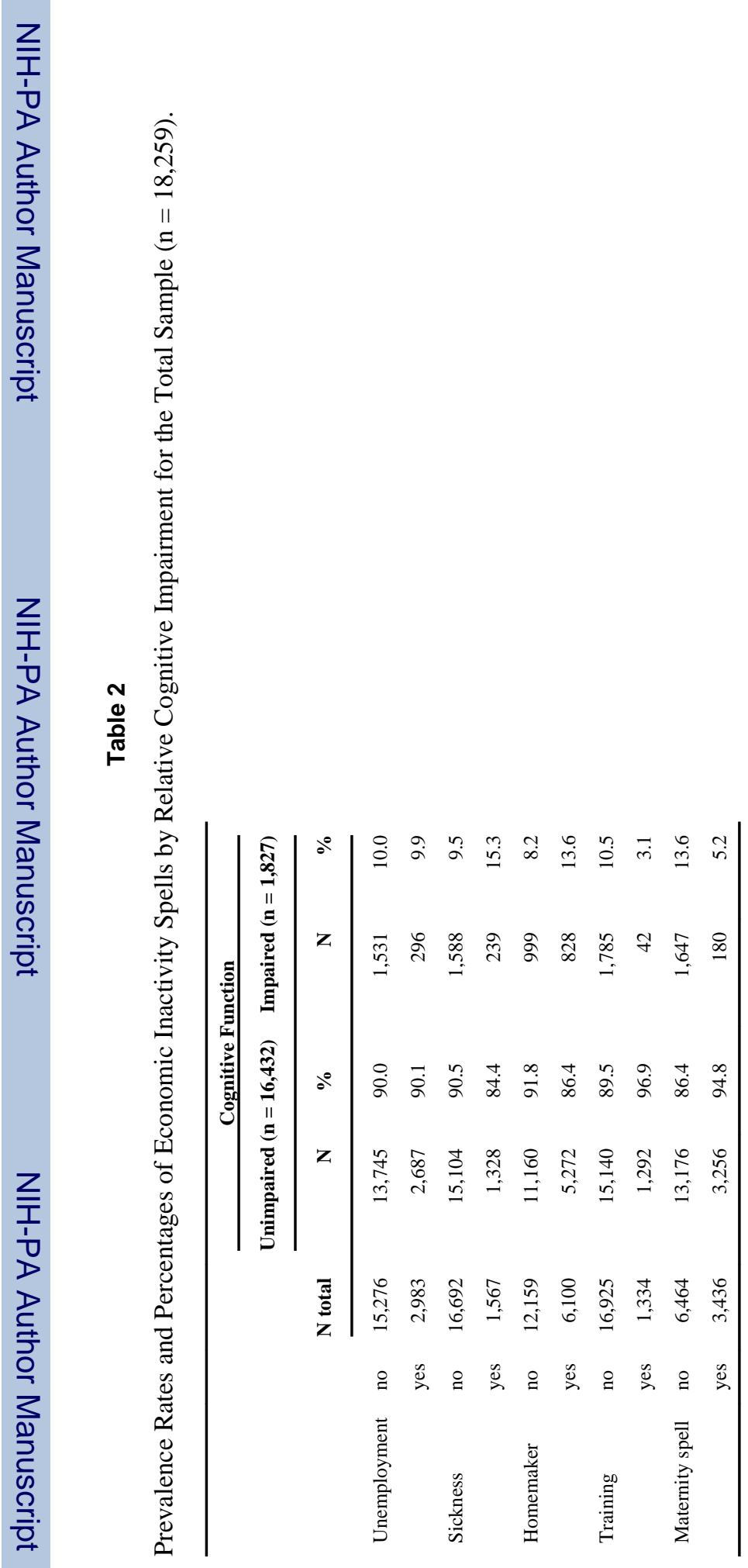

Ann Epidemiol. Author manuscript; available in PMC 2014 August 01. 


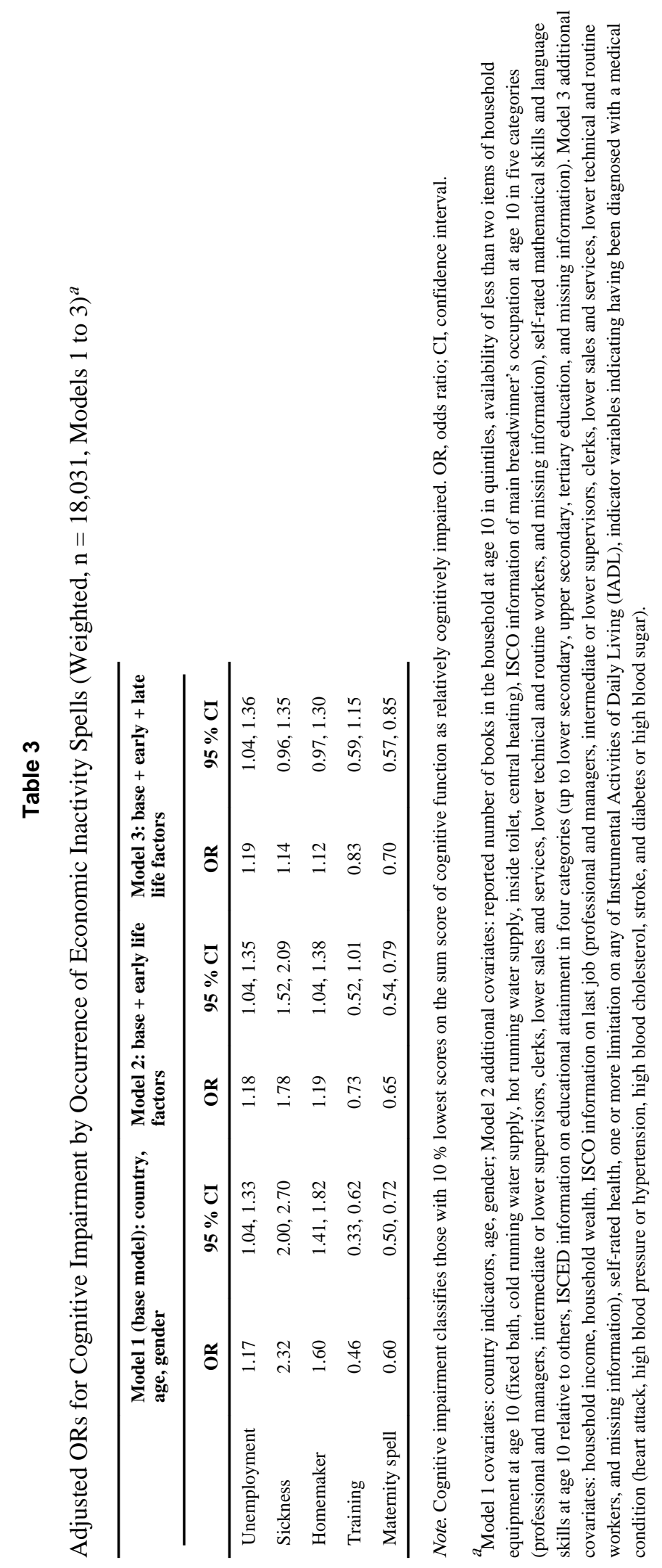

Ann Epidemiol. Author manuscript; available in PMC 2014 August 01. 


\section{Table 4}

Mixed Effects Model with Random Intercept and Fixed Effects Age in Decades, Gender, Country, Occurrence of Economic Inactivity Periods, and Age $\times$ Occurrence of Economic Inactivity Interaction (Weighted, $\mathrm{n}=$ 18,030, Model 1).

\begin{tabular}{lrrrr}
\hline \multicolumn{5}{c}{ Model 1 } \\
\hline B & 95 \% CI & & P value \\
\hline Age in decades & -0.224 & -0.238, & -0.210 & $<0.001$ \\
Unemployment & -0.088 & -0.126, & -0.051 & $<0.001$ \\
Age*unemployment & 0.057 & 0.020, & 0.093 & $<0.01$ \\
Age in decades & -0.220 & -0.233, & -0.206 & $<0.001$ \\
Sickness & -0.309 & -0.363, & -0.255 & $<0.001$ \\
Age*sickness & 0.089 & 0.041, & 0.137 & $<0.001$ \\
Age in decades & -0.200 & -0.215, & -0.183 & $<0.001$ \\
Homemaker & -0.117 & -0.151, & -0.083 & $<0.001$ \\
Age*homemaker & -0.013 & -0.040, & 0.014 & 0.35 \\
Age in decades & -0.219 & -0.232, & -0.205 & $<0.001$ \\
Training & 0.049 & -0.007, & 0.104 & 0.09 \\
Age*training & 0.105 & 0.053, & 0.157 & $<0.001$ \\
Age in decades & -0.269 & -0.298, & -0.240 & $<0.001$ \\
Maternity spell ${ }^{a}$ & -0.037 & -0.092, & 0.018 & 0.190 \\
Age*maternity spell & 0.098 & 0.048, & 0.148 & $<0.001$ \\
\hline
\end{tabular}

Note. CI, confidence interval. Coefficients for country and gender not shown.

${ }^{a}$ Analysis with female sample of $n=9,964$. 


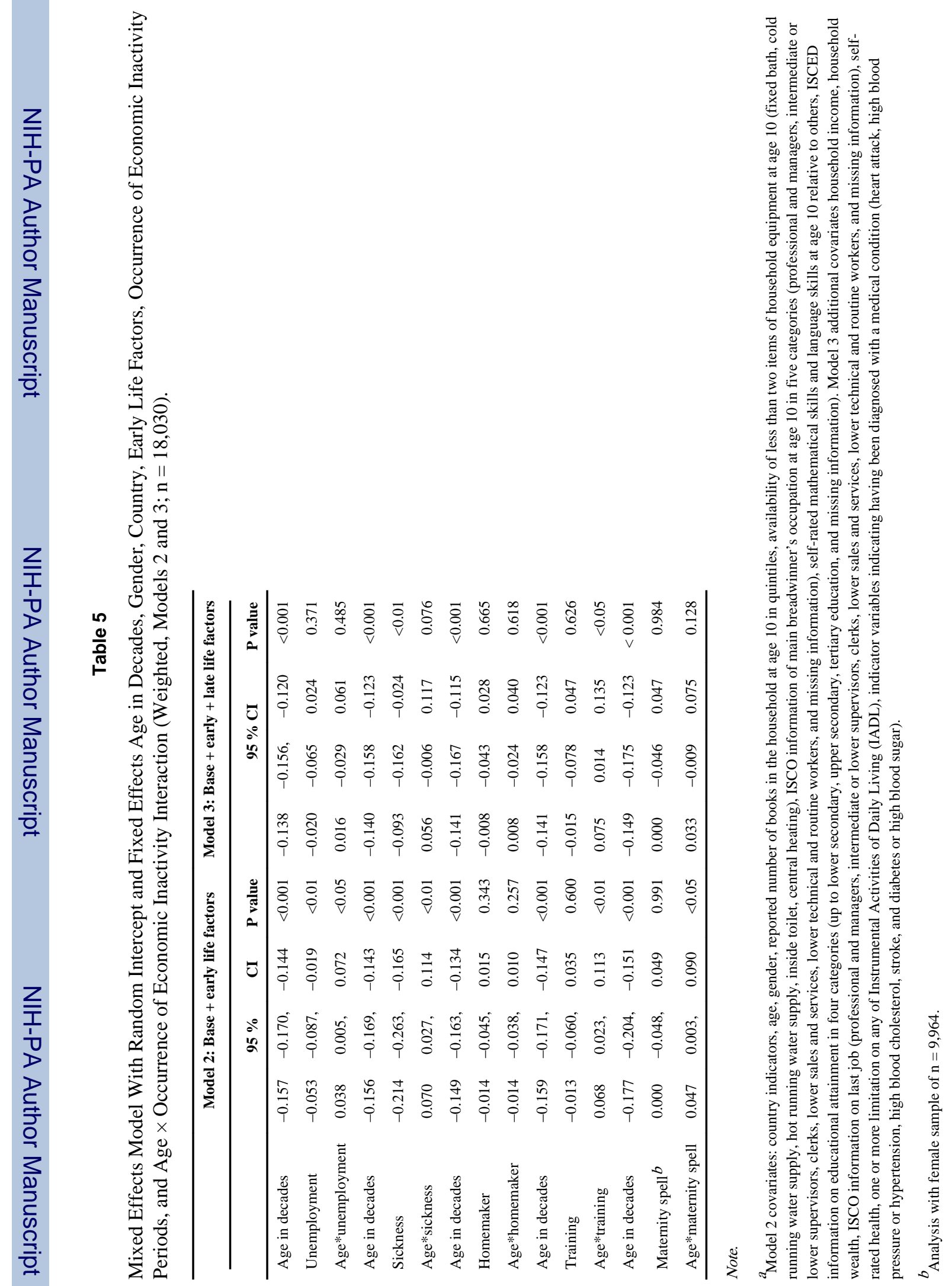




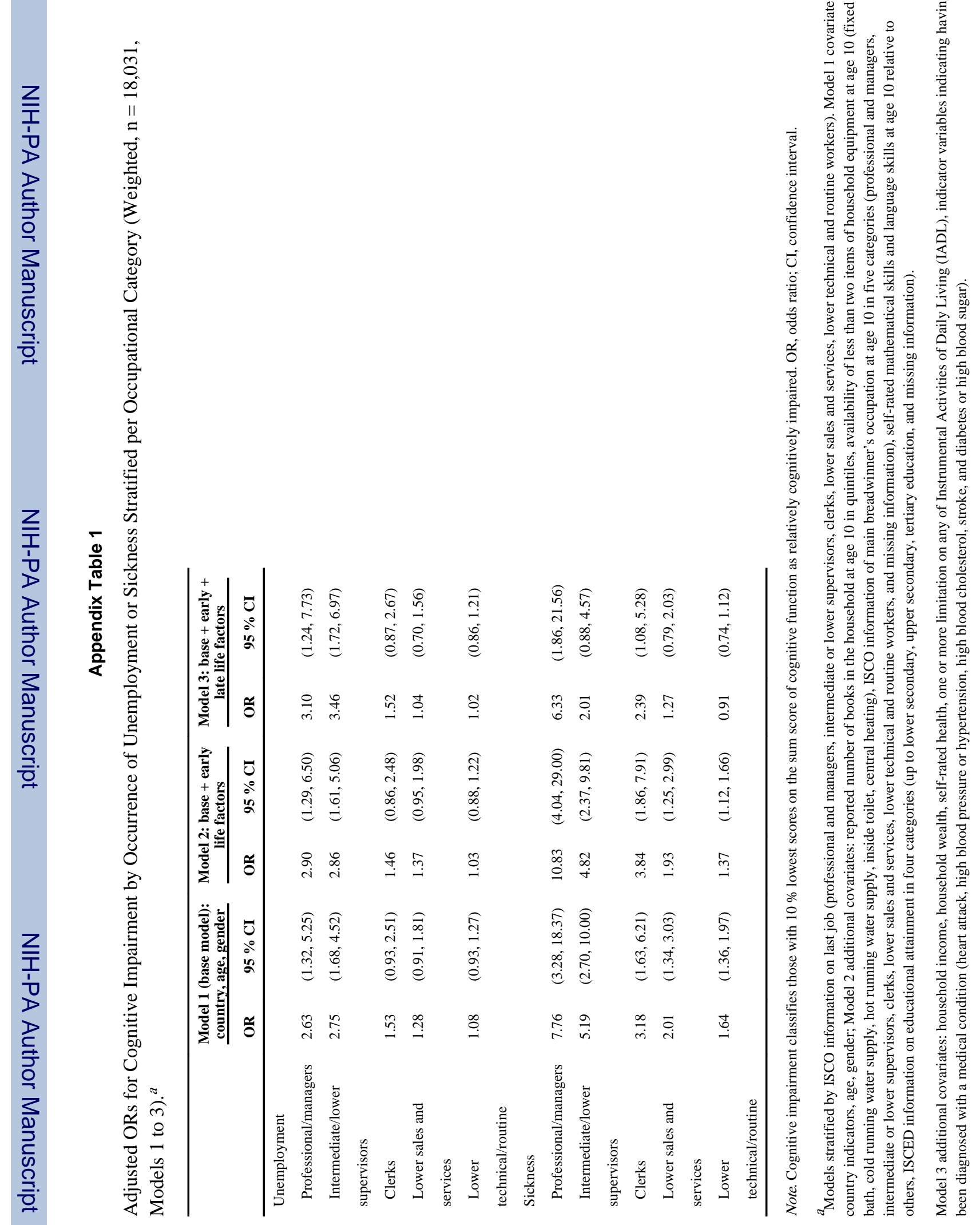

